\title{
Toward Effect of Digital Advertisement on Mobile Users in Middle East
}

\author{
Ismail Salamah ${ }^{1} \& \mathrm{Heng} \mathrm{Ma}^{1}$ \\ ${ }^{1}$ Chung Hua University, Hsinchu, Taiwan \\ Correspondence: Ismail Salamah, Chung Hua University, Hsinchu, Taiwan.
}

Received: June 5, 2017

Accepted: June 19, 2017

Online Published: November 13, 2017

doi:10.5430/ijba.v8n7p49

URL: https://doi.org/10.5430/ijba.v8n7p49

\begin{abstract}
Nowadays smart-phones are the part of daily life for around the worlds but when user is using the smart-phone service over internet to collect the information or to use other services, there are lots of advertisement pops up on the screen that effect the users in many ways. The purpose of this study was to find out the effectiveness of the mobile advertisement on the consumer behavior in Middle East and reaction over advertisement, that how different people would act or what would be their response upon receiving the mobile advertisement. However, the use of smart phone advertisements in Middle East has not reached the expectations due to several factors. To complete the task, data was collected through questionnaire and this questionnaire was distributed among 300 people that means the sample size was 300. To interpret and analyze the data, Correlation and regression analysis were used where the results showed that the consumers generally have negative attitude toward the mobile advertisement unless the advertisers had specifically taken the consent of the consumer. The relation is both positive and negative and could vary according to the conditions.
\end{abstract}

Keywords: consumer behavior, effective advertisement, mobile advertisement, positive and negative impact

\section{Introduction}

Consumers' attitudes toward an ad (Aad) have offered a critical theoretical construct since 1981, with the publication of two influential articles (Mitchell \& Olson, 1981; Shimp, 1981). Following these seminal articles, various studies were dedicated to demonstrating the effects of Aad on brand attitudes and purchase intentions(Gardner, 1985; MacKenzie, Lutz, \& Belch, 1986). Other studies show that Aad notably depends on attitudes toward advertising in general (Lutz, McKenzie, \& Belch, 1983; Muehling, 1987; MacKenzie \& Lutz, 1989; Mehta, 2000). A lot of studies show that Attitude toward the advertising depends on attitudes toward advertising in general. Attitudes toward advertising in general and their influence on advertising effectiveness have rarely been studied in cross-national studies (Mehta, 2000). The user acceptance of smart phone advertisements is critical to the growth of the business. The user acceptance is defined by TRA (theory of reasoned action) as the degree to which a user comes to accept and use a technology. Based on the correlation between the consumers' intention and their behavior founded by TRA, we believe that finer user acceptance indicates increased willingness to use smart phone advertisements. Mobile is a common device which is in use of almost all the people. In early days it was considered only for the purpose of communication, to be in contact with the people to whom you are close or with the people for business purposes. Now days it is used for multi purposes and has become the need of every person. Mobile phone is now used for many business activities, to keep in touch with what is happening around in the world, for internet access, for security and doing many tasks through various applications, for entertainment and for many more purposes. The mobile phone is one of a handful of consumer products to have gained global acceptance within a relatively short period of time (Barnes \& Scornavaca, 2004). The mobile phone is not only a personal device used to stay connected with friends and family, but also an extension of their personality and individuality (Grant \& Donohoe, 2007; Sultan \& Rohm, 2005).

Nowadays another use of mobile is the mobile marketing. Mobile marketing is actually the advertisement through mobile phones provide information, knowledge and awareness about your product to the people and also capturing your target market through the mobile advertisement. This trend or method is however new but it is getting familiar now. For marketers, the widespread adoption of mobile phones represents a huge marketing opportunity to reach and serve consumers anytime, anywhere (Barutcu, 2007; Grant \& Donohoe, 2007; Roach, 2009; Sultan \& Rohm, 2005). Mobile marketing is still in its early stages and mobile marketing practices will likely go through fundamental changes as the technology continues to evolve(Karjaluoto, Lehto, Leppaniemi, \& Jayawardhena, 2008). Now we talk 
about the consumer behavior that what would be the attitude of consumer and what would be his behavior towards the mobile advertisement either his response would be positive or negative when he would actually receive the advertisement in the form of call, text message or MMS. Any individual who purchases goods and services from the market for his/her end-use is called a consumer. Every customer shows inclination towards particular products and services.

Mobile advertising is a big business. This year in 2016 in the US, advertisers will spend \$28.72 billion to reach their targets on mobile devices, eMarketer estimates, an increase of 50.0\% over 2014 spending levels. But-as is common with so many digital advertising channels that offer the promise of measurability and ever-increasing efficacy_performance measurement is still a challenge (Milward Brown Digital, 2015). Among agencies surveyed worldwide in February 2015 (Econsultancy, 2015), 38\% said mobile marketing had excellent or good ROI (return on investment); $35 \%$ of client-side marketers said the same. In January, US marketers polled by the Direct Marketing Association and Demand Metric reported a median 12\% to 14\% ROI for mobile. In 2015 research (Inmobi, 2015) about how marketers measured mobile native ad effectiveness found an emphasis on click through rates $(56 \%$ of respondents worldwide), engagement rate (51\%), conversion rate $(45 \%)$ and cost per conversion $(40 \%)$. Among business-to-business marketers surveyed worldwide by Regalix in May, 79\% tracked web traffic, 71\% social media sharing, and $64 \%$ click through rates on their mobile marketing efforts. And according to comScore, last year brand lift metrics for mobile ads ranged from a low of $2.5 \%$ lift in aided awareness to a high of $4.3 \%$ lift in both likelihood to recommend and purchase intent.

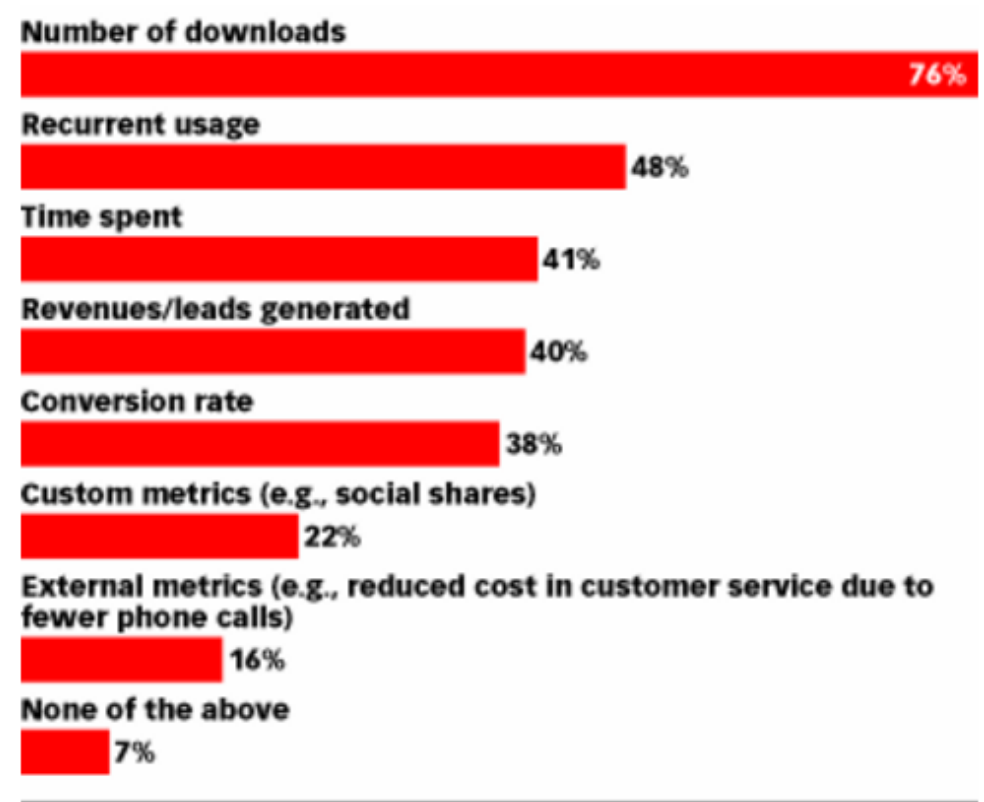

Figure 1. Metrics used to measure mobile app success, according to client side marketers worldwide, 2015

Source: (Econsultancy), Quarterly digital intelligence briefing: The quest for mobile excellence in association with adobe, April 29, 2015 


\begin{tabular}{|l|r|r|}
\hline Clickthrough rate (CTR) & $56 \%$ \\
\hline Engagement rate & $51 \%$ \\
\hline Conversion rate & & \\
\hline Cost per conversion & $45 \%$ & \\
\hline Number of interactions & $33 \%$ & \\
\hline Brand lift & $26 \%$ \\
\hline Number of shares & $25 \%$ \\
\hline Brand recall & $19 \%$ \\
\hline Dwell time & $18 \%$ & Message association \\
\hline
\end{tabular}

Figure 2. Metrics used to measure the effectiveness of native advertisement, according to marketers worldwide, 2015 Source: (Inmobi), Marketers and Publishers perception, native advertiser on mobile, April 06, 2015

Consumer interest is nothing but willingness of consumers to purchase products and services as per their taste, need and of course pocket and consumer behavior is a branch which deals with the various stages a consumer goes through before purchasing products or services for his end use (Management study guide, n.d.). As mobile marketing is increasing now a days so more research is needed to explore this method of marketing and the consumer behavior and attitude. Many researchers have presented their works in this area of study. This focus to know about the consumer behavior that how would it be affected through the mobile marketing and how to develop the various strategies to do the successful marketing by viewing, especially in the Jordon markets. The remaining part of this article is structured as: The next section will provide a brief literature review on mobile marketing. Then there is a discussion of our framework and hypothesis. Then there would be description of research method, presentation of result and discussion of our findings by making the conclusion.

\section{Literature Review}

Bogart (1985) found that advertising through both channels like internet and other media like TV, newspapers and magazines can easily ignored by the viewers because of very limited time and resources make them difficult to get right information through advertisement. However latest studies have different ideas all these Medias like internet have become proven median for advertising and also a good alternative of TV and newspapers. With the passage of time mobile devices have become more common among people due to its use in more industrialize countries. As mobiles give a great revolution among the communication of people it has also change the marketers view towards the customers now there is more and easy interaction held between marketer and customer.

Effects of advertising activities are influenced by consumer attitude towards advertising message, advertising company and media. If the companies want to convey their message through mobile media first they really need to understand how consumers perceive and evaluate the mobiles as a source of advertising. Mobile advertising allows marketers to give medium's unique features in order to customize their message to consumer's attributes (Houston \& Gassenheimer, 1987). Nowadays mobile marketing provide a great chance for business. Mobile devices have provided chance to the companies to communicate directly to their customers without any type of barrier like time or location. Through mobile devices information can be provided to the customers of their interest which gives chance to the marketers to build the customer relationship in new dimension that's way now a day's many companies rely on these types of devices to advertise and promote their products and services to their target customers. But most of the potential customers are unaware with the effective use of mobile devices in order to gain information from ads. A high degree of pleasure and involvement during the ads which are related to computer based media can get the positive reaction and good mood of consumer.

For the mobile market entertainment is also important if the message would be concise and funny it will immediately capture the consumer's attentions (Wang, Zhang, Choi, \& Eredita, 2002). According to me providing games and prizes via text messages will generate high attention of the customers. Features like entertainment use to make the 
customers more attentive towards advertising message.

We have taken the mobile advertisement as independent variable and consumer buying behavior, consumer mood and consumer acceptance as dependent variables in this study. There is a positive relationship between the advertisement and the buying behavior of the consumer. The response of the consumer might be positive when the products that are being offered are according to his/her taste and would be negative when the products are not according to his nature i.e. old fashioned people might not like the modern products. Similarly there would be more consumer acceptance when the advertisement is timely done and the situation would be favorable. If the condition would not be favorable for the consumer at that time then there would be less consumer acceptance.

In this study I just want to know the exact behavior of people towards advertisement either it influence people or not in order to generate profit for the organizations. I just also want to know the how much mobile phone is effective for the advertisement. This study was held in different parts of the country in Jordon and also in many other countries of the world and become able to judge the behavior of people regarding to mobile advertisement.

\section{Research Objectives}

Although this article already revealed the information about the advertisement and related companies to play on smart mobile and effect on consumers. Many researchers worked and working to calculate the effect of online or mobile advertisement on consumer but the objective of this research is to find out the effectiveness of advertisement on consumer behavior, find out the influence of culture on consumer behavior towards advertisement, to do the critical review of research papers on consumer attitude towards advertisement and the acceptance or rejection of advertisement by consumers. This research is conducted in Jordon.

The researcher used the survey research method. In this research, three different questionnaires were designed as the method for collecting the information about the mobile advertising from all aspect, advertiser (company), publisher (mobile app) and the audience (mobile users). The responded will response the agree/disagree matrix which is categorized into 5 degrees :

- Strongly agree

- Agree

- Neutral

- Disagree

- Strongly disagree

A total number of three hundred questionnaires were distributed into the three aspect of the mobile advertising process as shown in table.1 Cochran theorem were applied to determine the size of representative sample, the publisher (mobile app) were the less amount of participant in the research method because we found that there are few apps owner.

Table 1 shows that the return data from the audience is $210(63 \%)$ and 22 questionnaire were found as invalid data, and from the advertiser is 60 (19\%) And finally the table shows that the return data from the publisher is $30(10 \%)$, the rate of the invalid data does not affect the study, because it is insignificant compared to the number of the respondents' data, the analysis of the data that were obtained from the questionnaire that were found it is usable. After applying Cronbach's Alpha Coefficient using SPSS Software version 18 the amount of the Coefficient for the model was estimated 0.808. Cronbach's Alpha Coefficient states that an amount more than 0.70 implies that the test is reliable, so the mentioned amount means the model reliability is high. We have applied two statistical software's namely SPSS and R statistical to analyze the gathered data.

Regarding to our research the first part of our questioner were related to the mobile ads advertising, participant were asked if they pay attention to the mobile advertising, clicking on the apps ads and whether if they are using mobile apps or not. The second part were designed to find out the participant attitude toward the digital advertisement and the factor that influence the acceptance of the mobile advertisement and the digital advertisement process the result shows that the security of the digital advertisement strongly effect the consumer action toward the digital advertisement .

\section{Theoretical Framework}

\subsection{Independent Variable Dimensions}

Mobile advertisement is an independent variable. It has the following elements: 
Entertainment: Entertainment is the element of the mobile advertisement. Entertainment generally means to get amused by something. Hereby we will see the impact of entertainment on the consumer behavior. Most of the consumers like children and people of young age like the factor of entertainment in any type of ad But the actual consumers are the adults and old people and they mostly do not like the factor of entertainment.

In Formativeness: In formativeness means how much information is provided to the consumers. It is necessary that complete and comprehensive information must be provided to the consumers. The more the information provided to the consumers the more they will recognize your product and this recognition may leads towards their buying behavior.

Irritability: Irritability is the factor that counts the most in the mobile advertisement. It should be kept in mind that while doing the advertisement the factor of irritability must be kept very low. The greater the factor of irritability, the less will be the consumer acceptance of the advertisement.

\subsection{Dependant Variable}

Consumer Behavior: Consumer behavior is the dependent variable in this study in this study. Consumer behavior is the behavior of that person that he shows while receiving the ads. This consumer behavior, if narrowed down, contains consumer buying behavior, consumer mood and consumer acceptance. All these factors depend upon the way you are doing your mobile advertisement. If the mobile advertisement will be done in an effective manner then overall behavior of the consumers would be good and his response would be more positive. And if the advertisement strategy that you have adopted would not be good then the consumer might got irritate and show his behavior negatively.

\section{Hypothesis}

H1: There is a no relationship between the consumer behavior and mobile messages entertainment.

H2: There is positive relationship between the consumer behavior and in formativeness of mobile ads.

H3: There is a no relationship between the consumer behavior and mobile messages irritability.

\section{Materials and Methods}

\subsection{Data Collection Method}

The research was based on primary and secondary data sets. Primary data was collected from the field by taking some interviews, through questionnaire and through different surveys and secondary data was collected from all the other researches held by some other people. Analysis was based on the critical review of these reports and visiting the sites of these research papers. In order to get the desire answers a questionnaire was held in Jordon.

We used the quantitative approach to collect the data and had taken the sample of 300; the response of the people was $100 \%$. The questionnaire was not adopted so there could be doubt on its reliability. The liability test was applied to check the reliability of the data.

\subsection{Data Analysis}

Descriptive and inferential statistics were applied for the analysis of the data. Mean and standard deviation of the dimensions of the data were calculated. Alpha test was applied to check the reliability of the data. Correlation analysis was used to check that how much the dimensions of consumer behavioral correlated with one another. Regression analysis was used to calculate how much the percent change occurred by the mobile advertisement on the behavior of the consumers.

\section{Results}

\subsection{Results of Descriptive Statistics}

Results of demographic characteristics of respondents were shown in percentage in the form of tables.

Table 1. Descriptive statistics

\begin{tabular}{cccc}
\hline Aspect & Total participant & Invalid date & Percentage \\
A - Audience & 210 & 22 & $63 \%$ \\
B - advertiser & 60 & 3 & $19 \%$ \\
C - Publisher & 30 & 1 & $10 \%$ \\
Total & 300 & 26 & $92 \%$ \\
\hline
\end{tabular}




\section{Interpretation:}

H1: The above results show that there is no relation between consumer behavior and the entertainment because there is no significance in their relationship. $(\mathrm{r}=.055)$. This hypothesis is accepted.

H2: The above results shows that there is positive relationship between consumer behavior and in formativeness of ( $\mathrm{r}$ $\left.=.195^{*}\right)$ at significance level of 0.01 but this relation is weak. This hypothesis is also accepted.

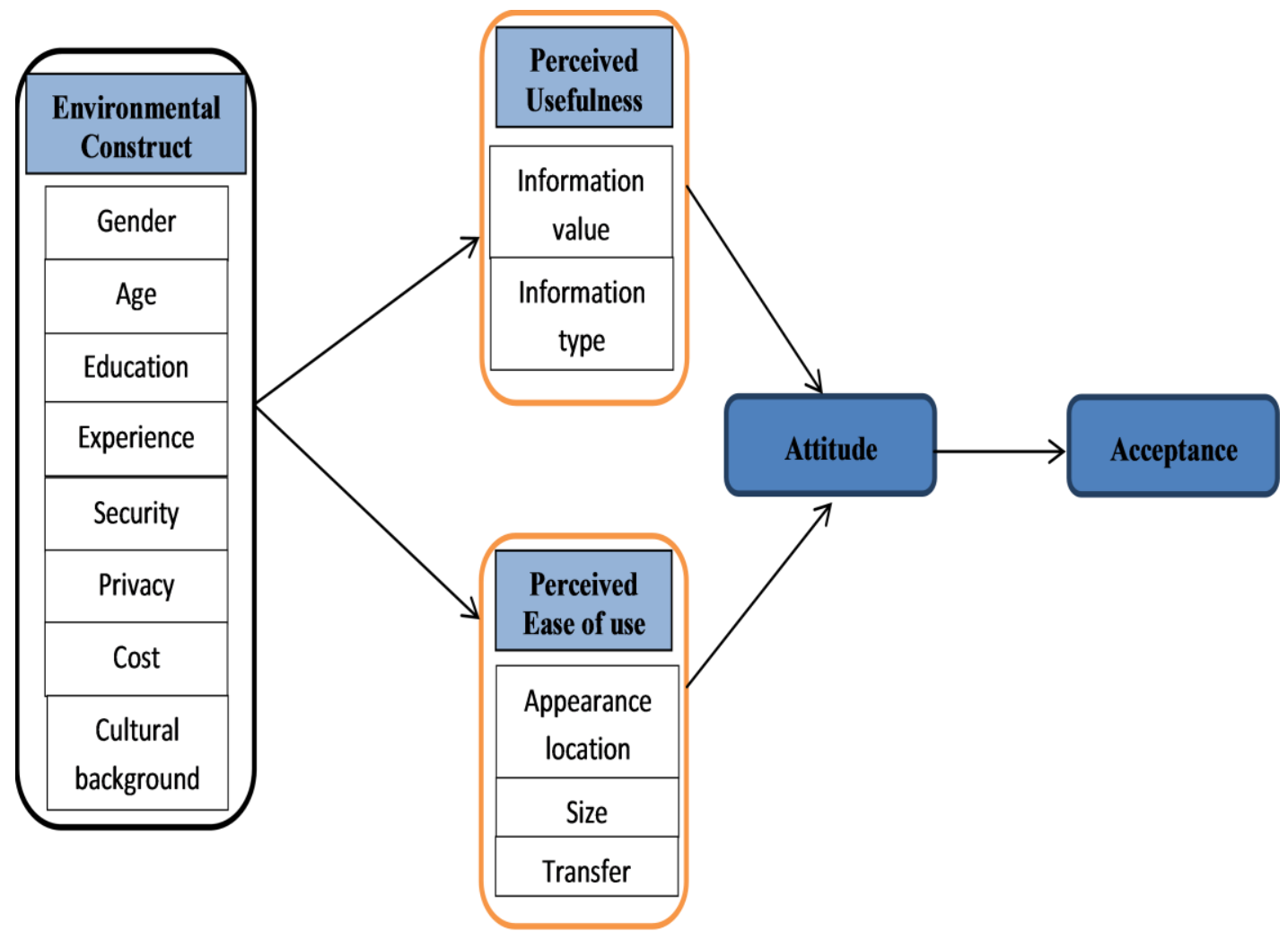

Figure 3. The model

Table 2. Result of Reliability Analysis

\begin{tabular}{llc}
\hline NO & Dimension & Cronbach's Alpha \\
\hline 1 & Reliability & 0.531 \\
Gender & Frequency & $\%$ \\
Male & 91 & 30.3 \\
Female & 209 & 69.7 \\
Total & 300 & 100 \\
\hline
\end{tabular}


Table 3. Correlation

\begin{tabular}{|c|c|c|c|c|c|c|}
\hline & Mean & S.D & C_B & A_E & A_I & A_IR \\
\hline C_B & 1.8400 & .85984 & 1 & & & \\
\hline A_E & 2.4433 & .65676 & .055 & 1 & & \\
\hline A_I & 2.6433 & .61670 & $.195 *$ & $.273^{* *}$ & 1 & \\
\hline A_IR & 2.7711 & .69098 & .066 & $.324 * *$ & .319 & 1 \\
\hline
\end{tabular}

$*=$ Correlation is significant at the 0.05 level (2-tailed)

$* *=$ Correlation is significant at the 0.01 level (2-tailed)

Table 4. Result

\begin{tabular}{llcc}
\hline Item & Proposed Effect & Beta Co-efficient & P-Value \\
\hline Mobile Advertisement (Adjust R Square = .019) & & .951 \\
\hline H1: Entertainment & - & -.005 & .026 \\
\hline H2: Reliability & + & .191 & .766 \\
\hline H3: Irritability & + & .026 & \\
\hline
\end{tabular}

H3: The above results shows that there is no relationship between consumer behavior and irritation of $(r=.066)$ and there is no significance. Hence this hypothesis is accepted.

\section{Interpretation:}

H1: The above results shows that there is negative relationship between consumer behavior and entertainment hence it are rejected.

H2: The above results show there is no positive relationship between consumer behavior and in formativeness hence it rejected.

H3: The above results show there is no relationship between consumer behavior and irritation hence it is accepted.

\section{Conclusion}

This study was conducted to explore the effect on consumer's attitudes towards digital smart-phone advertisement. The current study concluded that the majority of our respondents have a negative attitude on it. Respondents believe that digital advertisement didn't respect their privacy and it could show off any time while they are surfing the internet or their smart-phone. The result shows that the majority of the respondents have a negative attitude and they think that digital advertisements are not useful in Jordan. I have used the quantitative method for the collection of data and had designed the questionnaire for this purpose. I have taken the sample of 300 and applied the correlation and regression methods for the interpretation of data. This study was conducted in Jordon.

The overall result that I got is both positive and negative. This shows that there is both positive and negative relation between the consumer behavior and the mobile advertisement.

Limitations: In this study the sample size of 3000 has taken. The result could be more accurate and liable if a larger sample had taken, but there was the constraint of time and resources. The regression and the correlation tests were applied; result could be more liable if some other tests had been applied. The sample was taken only from the city in Jordon, Results could be more liable if the no is to be collected from other cities, so it was also a constraint.

\section{References}

Barnes, S. J., \& Scornavaca, E. (2004). Mobile marketing: The role of permission and acceptance. International Journal of Mobile Communications, 2(2), 128-139. http://doi.org/10.1504/IJMC.2004.004663

Barutcu, S. (2007). Attitudes towards mobile marketing tools : A study of Turkish consumers. Journal of Targeting, Measurement and Analysis for Marketing, 16(1), 26-38. http://doi.org/10.1057/palgrave.jt.5750061

Bogart, L. (1985). War of the Words: Advertising in the Year 2010. Across the Board.

Econsultancy. (2015). Quarterly Digital Intelligence Briefing: The Quest for Mobile Excellence. Retrieved June 1, 
2017,

from

https://econsultancy.com/reports/quarterly-digital-intelligence-briefing-the-quest-for-mobile-excellence/

Gardner, M. P. (1985). Does Attitude toward the Ad Affect Brand Attitude under a Brand Evaluation Set? Journal of Marketing Research, 22(2), 192-198. http://doi.org/10.2307/3151364

Grant, I., \& Donohoe, S. O. (2007). Why young consumers are not open to mobile marketing communication. International Journal of Advertising, 26(2), 223-246. Retrieved from loc.llas.ac.uk/lob/220/.../MobileMarketingCommunication.pdf

Houston, F. S., \& Gassenheimer, J. B. (1987). Marketing and Exchange. Journal of Marketing, 51(4), 3-18. http://doi.org/10.2307/1251244

Inmobi. (2015). Marketer and Publisher Perceptions: Native Advertising on Mobile. Retrieved June 1, 2017, from http://www.inmobi.com/insights/download/whitepapers/marketer-and-publisher-perceptions-native-advertisingon-mobile/

Karjaluoto, H., Lehto, H., Leppaniemi, M., \& Jayawardhena, C. (2008). Exploring Gender Influence on Customer 's Intention to Engage Permission-based Mobile Marketing. Electronic Markets, 18(3), 242-259. http://doi.org/10.1080/10196780802265793

MacKenzie, S. B., Lutz, R. J., \& Belch, G. E. (1986). The Role of Attitude toward the Ad as a Mediator of Advertising Effectiveness: A Test of Competing Explanations. Journal of Marketing Research, 23(2), 130-143. http://doi.org/10.2307/3151660

Management study guide, E. (n.d.). Consumer Behaviour - Meaning, Determinants and its Importance. Retrieved December 15, 2012, from http://www.managementstudyguide.com/consumer-behaviour.htm

Mehta, A. (2000). Advertising Attitudes and Advertising Effectiveness. Journal of Advertising Research, 40(3), 67 LP-72. Retrieved from http://www.journalofadvertisingresearch.com/content/40/3/67.abstract

Milward Brown Digital. (2015). Measuring Mobile Effectiveness Still Challenges Marketers Management — How Marketing-Data- Management-. Retrieved June 1, 2017, from https://www.emarketer.com/Article/Measuring-Mobile-Effectiveness-Still-Challenges-Marketers/1012797

Mitchell, A. A., \& Olson, J. C. (1981). Are Product Attribute Beliefs the Only Mediator of Advertising Effects on Brand Attitude? Journal of Marketing Research, XVIII(August), 318-333. Retrieved from https://www.emarketer.com/Article/Measuring-Mobile-Effectiveness-Still-Challenges-Marketers/1012797

Roach, G. (2009). Consumer perceptions of mobile phone marketing: a direct marketing innovation. Direct Marketing: An International Journal, 3(2), 124-138. http://doi.org/10.1108/17505930910964786

Shimp, T. A. (1981). Attitude toward the AD as a Mediator of Consumer Brand Choice. Journal of Advertising, 10(2), 9-48. http://doi.org/10.1080/00913367.1981.10672756

Sultan, F., \& Rohm, A. (2005). The Coming Era of " Brand in the Hand " Marketing. MIT Sloan Management $47(1)$, 83-89. Retrieved

from http://sloanreview.mit.edu/article/the-coming-era-of-brand-in-the-hand-marketing/

Wang, C., Zhang, P., Choi, R., \& Eredita, M. D. (2002). Understanding Consumer Attitude Toward Advertising. In Eighth Americas Conference on Information Systems (pp. 1143-1148). Retrieved from melody.syr.edu/hci/amcis02_minitrack/RIP/Wang.pdf 